\title{
THE EMISSION LINES IN THE SPECTRA OF B 1985 AND WY GEMINORUM*
}

\author{
P. SWINGS AND O. STRUVE
}

\section{ABSTRACT}

The spectra of $\mathrm{B} \mathrm{I}_{985}$ and WY Gem show numerous emission lines in the ultraviolet region. These have been identified with $[F e \mathrm{II}], \mathrm{Fe}$ II, $[\mathrm{Cr}$ II], and $C r$ II. The permitted lines of $F e$ II and $C r$ II are relatively much stronger in $\mathrm{B} \mathrm{I}_{9} 85$ than in WY Gem. Lines of high excitation potential are relatively weaker in the stars than in the laboratory. The strength of forbidden $[F e$ II] in the shells of these stars suggests that the lifetimes of the metastable levels are considerably shorter than those of metastable levels of $[O \mathrm{I}],[N \Pi],[S \mathrm{II}]$, etc.

These two objects ${ }^{\mathrm{I}}$ are known to possess strong emission lines of ionized iron, both permitted and forbidden, and some of their characteristics have been recently discussed by the authors. ${ }^{2}$ In WY Gem the forbidden lines of $[F e$ II] are considerably stronger than the permitted $F e$ II lines of the photographic region, whereas, in B I985, the relative intensities of $F e$ II and [Fe II] are about the same as in $\eta$ Carinae. Each of the two objects consists of an M-type star and of a hot companion approximately of type $\mathrm{B}_{3} \mathrm{e}$. The authors have devoted several recent papers to the discussion of binaries of similar type, such as Z And, TC Br, AX Per, CI Cyg, a Sco, etc.; the present note is concerned with the bright lines not previously discussed. The observational material consists of (a) spectrograms on Eastman Process emulsion, extending from $\lambda 3900$ to $\lambda 4900$, taken with the glass spectrograph of the McDonald Observatory (dispersion $26 \mathrm{~A} / \mathrm{mm}$ at $H \gamma)^{3}$ and (b) spectrograms taken in the ultraviolet region from $\lambda_{3 \text { Ioo to }} \lambda_{3450}$ (dispersion $57 \mathrm{~A} / \mathrm{mm}$ at $\lambda 3220$ ).

Besides bright $\mathrm{H}$ and $\mathrm{K}$ lines which are weakly present in $\mathrm{B} \mathrm{I}_{9} 85$, the material shows the following emissions: (I) permitted and forbidden lines of $\mathrm{Fe}$ II; (2) permitted and forbidden lines of $\mathrm{Cr}$ II; and (3) a forbidden line of $S$ II.

\section{IONIZED IRON}

\section{A. PERMITTED LINES}

In the photographic region all the strong $F e$ II lines arise from excited levels between 5.3 and 5.6 volts, their lower levels lying between 2.6 and 2.9 volts. The photographic region is, therefore, not suitable for a discussion of the behavior of bright lines arising from widely separated excited levels. The situation is quite different in the region

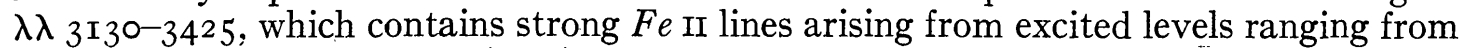
4.8 volts $\left(\mathrm{z}^{6} \mathrm{D}^{\circ}\right)$ to 8.6 volts $\left(\mathrm{y}^{2} \mathrm{~F}^{0}\right)$. Many $F e$ II lines have been observed in $\mathrm{B}$ I 985 and WY Gem in that region, and the results are summarized in Table $\mathrm{I}$, in which the lines have been classified according to increasing potential of the upper level.

This table clearly illustrates the effect of the excitation potential. A line of laboratory intensity ro gives a stellar line of estimated intensity 5 when the excited level is around

* Contributions from the McDonald Observatory, University of Texas, No. 34 .

${ }^{\mathrm{r}}$ Boss $1985=\mathrm{HD} 604 \mathrm{I} 4-604 \mathrm{I} 5 ;-\mathrm{I}^{\circ}{ }^{\circ} \mathrm{I} 97 \mathrm{I} ; a(\mathrm{r} 900) 7^{\mathrm{h}} 29^{\mathrm{m}_{2}} ; \delta(\mathrm{I} 900)-\mathrm{I}_{4}^{\circ}{ }^{1} 8^{\prime} ; m=5.2$. WY Geminorum $=\mathrm{HD}_{42474 ;}+23^{\circ}{ }^{\mathrm{I}} 243 ; a(\mathrm{I} 900) 6^{\mathrm{h}} \mathrm{O} 5^{\mathrm{m}} 8 ; \delta(\mathrm{I} 900)+23^{\circ}{ }^{\circ} 4^{\prime} ; m=7.4-7.9$.

${ }^{2} A$ p. J., 9r, 546, I940.

3 The spectrum of a Orionis was used for comparison, this spectrum being very similar to the late-type component of the two objects investigated. 
5 volts and a stellar intensity of only I when the excitation potential is around 8 volts. The intensities are, thus, quite different from those which we should expect if the re-

TABLE 1

PERMitTed LINES OF $F e$ II OBSERVED IN EMISSION BETWEeN

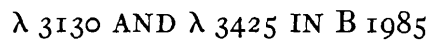

\begin{tabular}{|c|c|c|c|c|c|}
\hline \multirow{2}{*}{\multicolumn{2}{|c|}{ TRANSITIONS }} & \multicolumn{2}{|c|}{ LABORATORY } & \multirow{2}{*}{$\begin{array}{l}\text { INTENSITy } \\
\text { IN B }{ }^{9} 985\end{array}$} & \multirow{2}{*}{$\begin{array}{c}\text { RE- } \\
\text { MARKS }\end{array}$} \\
\hline & & \multirow{2}{*}{$\begin{array}{c}\lambda \\
3255.88 \\
3277.35 \\
328 \mathrm{I} .29 \\
3285.42 \\
3295.81 \\
3302.86 \\
3303.47\end{array}$} & $\frac{\text { Intensity }}{8}$ & & \\
\hline $\begin{array}{l}\mathrm{a}^{4} \mathrm{D}-\mathrm{z}^{6} \mathrm{D}^{0} \\
(\text { I. I v.) }(4.8 \mathrm{v} .)\end{array}$ & $\begin{array}{c}3 \frac{1}{2}-3 \frac{1}{2} \\
3 \frac{1}{2}-4 \frac{1}{2} \\
2 \frac{1}{2}-2 \frac{1}{2} \\
\mathrm{I}_{2}-\frac{1}{2} \\
\mathrm{I} \frac{1}{2}-1 \frac{1}{2} \\
2 \frac{1}{2}-3 \frac{1}{2} \\
\frac{1}{2}-\frac{1}{2}\end{array}$ & & $\left.\begin{array}{l}8 \\
9 \\
7 \\
3 \\
6 \\
4 \\
4\end{array}\right\}$ & $\begin{array}{l}3 \\
4 \\
3 \\
0 \\
\mathrm{I} \\
2\end{array}$ & I \\
\hline $\begin{array}{l}\mathrm{a}^{4} \mathrm{P}-\mathrm{Z}^{4} \mathrm{D}^{0} \\
(\mathrm{I} .7 \mathrm{v} .)(5.5 \mathrm{v} .)\end{array}$ & $\begin{array}{l}2 \frac{1}{2}-\mathrm{I} \frac{1}{2} \\
\mathrm{I} \frac{1}{2}-\frac{1}{2} \\
\mathrm{I} \frac{1}{2}-\mathrm{I} \frac{1}{2} \\
\frac{1}{2}-\frac{1}{2} \\
\frac{1}{2}-\mathrm{I} \frac{1}{2} \\
\mathrm{I} \frac{1}{2}-2 \frac{1}{2} \\
2 \frac{1}{2}-3 \frac{1}{2}\end{array}$ & $\begin{array}{l}3166.67 \\
3170.34 \\
3186.74 \\
3193.81 \\
3210.45 \\
3213.31 \\
3227.73\end{array}$ & $\begin{array}{l}4 \\
6 \\
\text { II } \\
\text { II } \\
\text { IO } \\
\text { I3 } \\
\text { I3 }\end{array}$ & $\begin{array}{c}I-O \\
I-0 \\
3-4 \\
5 \\
4 \\
5 \\
6\end{array}$ & 2 \\
\hline $\begin{array}{l}\mathrm{a}^{4} \mathrm{P}-\mathrm{z}^{4} \mathrm{~F}^{0} \\
(\mathrm{I} .7 \mathrm{v} .)(5.5 \mathrm{v} .)\end{array}$ & $\begin{array}{l}2 \frac{1}{2}-2 \frac{1}{2} \\
1 \frac{1}{2}-2 \frac{1}{2} \\
2 \frac{1}{2}-3 \frac{1}{2}\end{array}$ & $\begin{array}{l}3163.09 \\
3183.11 \\
3196.07\end{array}$ & $\begin{array}{r}5 \\
8 \\
\text { I0 }\end{array}$ & $\begin{array}{l}3 \\
4 \\
5\end{array}$ & 3 \\
\hline $\begin{array}{l}\mathrm{a}^{2} \mathrm{P}-\mathrm{z}^{4} \mathrm{P}^{\mathrm{o}} \\
(2.3 \mathrm{v} .)(5.8 \mathrm{v} .)\end{array}$ & $\mathrm{I} \frac{1}{2}-\frac{1}{2}$ & 3416.02 & 5 & $O-I$ & \\
\hline $\begin{array}{l}\mathrm{b}^{2} \mathrm{G}-\mathrm{z}^{4} \mathrm{H}^{0} \\
(3.8 \mathrm{v} .)(7.5 \mathrm{v} .)\end{array}$ & $3^{\frac{1}{2}}-3^{\frac{1}{2}}$ & 3289.35 & 7 & $I-O$ & 3 \\
\hline $\begin{array}{l}b^{2} \mathrm{~F}-z^{2} \mathrm{D}^{0} \\
(3.9 \mathrm{v})(7.6 \mathrm{v} .)\end{array}$ & $2 \frac{1}{2}-1 \frac{1}{2}$ & 3297.89 & 5 & $\circ$ & \\
\hline $\begin{array}{l}\mathrm{b}^{4} \mathrm{D}-\mathrm{y}^{4} \mathrm{~F}^{0} \\
(3.9 \text { v. })(7.7 \text { v. })\end{array}$ & $3 \frac{1}{2}-4 \frac{1}{2}$ & 3259.05 & Io & $O-I$ & \\
\hline $\begin{array}{l}\mathrm{b}^{2} \mathrm{G}-\mathrm{z}^{2} \mathrm{G}^{0} \\
(3.8 \mathrm{v} .)(7.7 \mathrm{v} .)\end{array}$ & $3 \frac{1}{2}-3 \frac{1}{2}$ & 3167.85 & II & I & \\
\hline $\begin{array}{l}b^{4} \mathrm{D}-\mathrm{x}^{4} \mathrm{D}^{0} \\
(3.9 \text { v.) }(7.8 \text { v. })\end{array}$ & $\begin{array}{l}2 \frac{1}{2}-2 \frac{1}{2} \\
3 \frac{1}{2}-3 \frac{1}{2}\end{array}$ & $\begin{array}{l}3135.36 \\
3177.53\end{array}$ & $\begin{array}{r}9 \\
10\end{array}$ & $\stackrel{O-I}{I}$ & \\
\hline $\begin{array}{l}c^{2} G-y^{2} G^{0} \\
(4 . \text { v v.) }(8.0 \text { v.) }\end{array}$ & $\begin{array}{l}3 \frac{1}{2}-3 \frac{1}{2} \\
4^{\frac{1}{2}}-4^{\frac{1}{2}}\end{array}$ & $\begin{array}{l}3162.80 \\
3187.29\end{array}$ & $\begin{array}{l}8 \\
8\end{array}$ & 3 & $\begin{array}{l}4 \\
4\end{array}$ \\
\hline $\begin{array}{l}\mathrm{c}^{2} \mathrm{D}-\mathrm{y}^{2} \mathrm{~F}^{0} \\
(4.7 \text { v.) }(8.6 \mathrm{v}) .\end{array}$ & $\begin{array}{l}2 \frac{1}{2}-2 \frac{1}{2} \\
\mathrm{I} \frac{1}{2}-2 \frac{1}{2}\end{array}$ & $\begin{array}{l}3175.08 \\
3180.16\end{array}$ & $\begin{array}{l}4 \\
7\end{array}$ & $\begin{array}{l}O-1 \\
I-2\end{array}$ & $\begin{array}{l}3 \\
3\end{array}$ \\
\hline
\end{tabular}

I. Possibly weakly blended.

3. Blend.

2. Major contribution of a blend.

4. Minor contribution of a blend.

combination process were predominant. A behavior of the observed type would be obtained in the case of excitation by electron collisions. 


\section{B. FORBIDDEN LINES}

Besides the new forbidden transitions given in our previous paper, ${ }^{2}$ among which the most prominent is $a^{4} F-b^{4} \mathrm{D}$, the present material provides the following information. In the photographic region two faint emission lines have been observed at $\lambda$ 4I I4.4 and $\lambda$ 4249.I; they may be identified as $\mathrm{a}^{4} \mathrm{~F}_{4 / 2}-\mathrm{b}^{2} \mathrm{H}_{5 / 2}(\lambda$ pred. $=4 \mathrm{II} 4.5)$ and $\mathrm{a}^{4} \mathrm{D}_{3 / 2}-$ $\mathrm{b}^{4} \mathrm{D}_{3 \%}(\lambda$ pred. $=4249 . \mathrm{I})$. In the far ultraviolet region we shall consider four forbidden multiplets (Table 2).

The forbidden transition $a^{6} \mathrm{D}_{4 \% 3}-\mathrm{b}^{4} \mathrm{D}_{3 \% 3}$ gives probably the major contribution to the stellar line; there is a permitted $F e$ Ir line at 3 I 75.08 (lab. int. 4), but it arises from the very high level $\mathrm{y}^{2} \mathrm{~F}^{0}$ at 8.6 volts; and, according to Table $\mathrm{I}$, it should not have any appreciable intensity in $\mathrm{B} I 985$. The identification of $\mathrm{a}^{6} \mathrm{D}_{3 \times 2}-\mathrm{b}^{4} \mathrm{D}_{23_{6}}$ is doubtful because of the discrepancy in wave length and because of the high stellar intensity. These results supersede our previous work on the same multiplet; in our first paper ${ }^{2}$ the stellar line

TABLE 2

FORBIDDEN LINES OF $F e$ II IN THE ULTRAVIOLET REGION OF B I985 AND WY GEM

\begin{tabular}{|c|c|c|c|c|c|}
\hline \multicolumn{2}{|c|}{ Transition } & $\lambda$ Pred. & $\begin{array}{c}\lambda \text { in } \\
\text { BI985 }\end{array}$ & $\begin{array}{l}\text { Intensity } \\
\text { in } \mathrm{B}_{1985}\end{array}$ & Remarks \\
\hline $\begin{array}{l}a^{6} D-b^{4} D \\
a^{6} D-b^{2} F \\
a^{6} D-b^{2} G \\
a^{4} F-c^{2} G\end{array}$ & $\begin{array}{l}4 \frac{1}{2}-3 \frac{1}{2} \\
3 \frac{1}{2}-2 \frac{1}{2} \\
3 \frac{1}{2}-2 \frac{1}{2} \\
4 \frac{1}{2}-4 \frac{1}{2} \\
4 \frac{1}{2}-4 \frac{1}{2} \\
3 \frac{1}{2}-3 \frac{1}{2}\end{array}$ & $\begin{array}{l}3 \mathrm{I} 75 \cdot 28 \\
3224 \cdot 54 \\
3 \mathrm{I} 8 \mathrm{I} \cdot 05 \\
3289 \cdot 76 \\
3 \mathrm{I} 64 \cdot 26 \\
32 \mathrm{I} 7 \cdot 5 \mathrm{I}\end{array}$ & $\begin{array}{l}3175 \cdot 3 \\
3223 \cdot 7 \\
3180.6 \\
3289.2 \\
3163 \cdot 1 \\
3217 \cdot 7\end{array}$ & $\begin{array}{c}O-I \\
2 \\
I-2 \\
I-O \\
4 n \\
I-O\end{array}$ & $\begin{array}{l}\text { Slightly blended } \\
\text { Doubtful identification } \\
\text { Blended } \\
\text { Minor contribution } \\
\text { Partial contribution in blend }\end{array}$ \\
\hline
\end{tabular}

$\lambda 3290$ had been attributed to $\mathrm{a}^{6} \mathrm{D}-\mathrm{b} 4 \mathrm{D}$, but it is presumably due to a permitted $\mathrm{Fe}$ II line.

The transition $\mathrm{a}^{6} \mathrm{D}_{3{ }_{3}}-\mathrm{b}^{2} \mathrm{~F}_{2 x_{6}}$ (from doublet to sextet) is possibly the major contributor to the stellar line $\lambda_{3}$ I80.6 (int. $\left.I-2\right)$. There is an $F e$ II line of intensity 7 at $\lambda_{3}$ I80.I6, but it again arises from the high level $\mathrm{y}^{2} \mathrm{~F}^{0}$ at 8.6 volts and should not produce a stellar intensity of $\mathrm{I}-2$; the identity remains uncertain.

The line $a^{6} D_{4 / 2}-b^{2} G_{4 \% /}$ gives only a minor contribution to a blend. In $a^{4} F-c^{2} G$, the transition $3 \frac{1}{2}-3 \frac{1}{2}$ appears to give the complete identification, whereas the line $4 \frac{1}{2}-4 \frac{1}{2}$ gives only a partial contribution to the observed stellar line. The present information with regard to $[F e \mathrm{II}]$ is summarized in Figure $\mathrm{I}$.

\section{IONIZED CHROMIUM}

In the ultraviolet region several permitted $\mathrm{Cr}$ II lines are observed in emission. The observations are summarized in Table 3.

A fairly strong, bright line measured in both objects at $\lambda$ 3993.Io may be attributed to $[\mathrm{Cr}$ II $], \mathrm{a}^{6} \mathrm{~S}_{2{ }_{2}}-\mathrm{b}^{4} \mathrm{D}_{3{ }^{3}}$, as has been mentioned previously; ${ }^{2}$ the excitation potential of $\mathrm{b}^{4} \mathrm{D}$ is $3 . \mathrm{I}$ volts.

\section{IONIZED SULPHUR}

A bright line has been measured in both objects at $\lambda$ 4068.56. This is the strongest component of the transauroral pair of $[S \mathrm{II}]$ (exc. pot. 3.0 v.). In WY Gem a line had been measured by Redman ${ }^{4}$ at $\lambda 4068.8$ and attributed tentatively to $[F e$ II]. The attribution to $[S \mathrm{II}]$ is now beyond any doubt.

${ }^{4}$ Pub. Dom. Ap. Obs., Victoria, 6, 34, I93 I; M.N., 92, I I8, I932. 


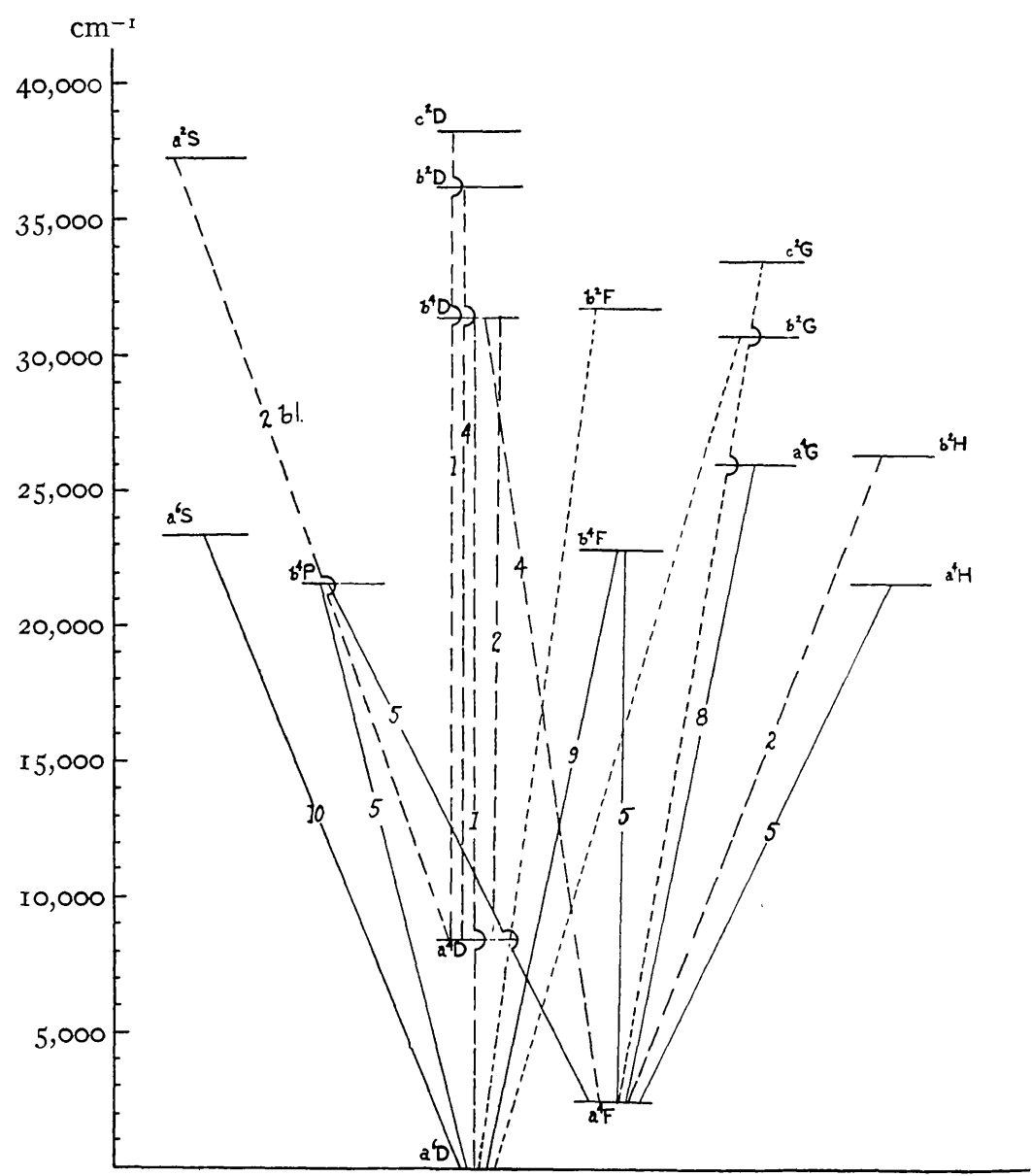

FIG. I.-Forbidden lines of $F e$ II observed in $\mathrm{B} \mathrm{I}_{9} 85$ and WY Gem. Full drawn lines: forbidden transitions observed previously in other stars; dashed lines: new observed lines; and dotted lines: transitions probably present.

TABLE 3

PERMITTED LINES OF $C r$ II OBSERVED IN EMISSION IN B I985

\begin{tabular}{|c|c|c|c|c|}
\hline \multicolumn{2}{|c|}{ TRANSITIONS } & \multicolumn{2}{|c|}{ LABORATORY } & \multirow{2}{*}{$\begin{array}{c}\text { INTENSITY } \\
\text { IN B Ig85 } \\
\begin{array}{c}\text { O-I } \\
\text { I-2 } \\
2\end{array}\end{array}$} \\
\hline $\begin{array}{l}\mathrm{a}^{4} \mathrm{D}-\mathrm{z}^{4} \mathrm{P}^{0} \\
(2.4 \mathrm{v} .)(6 . \mathrm{I} \mathrm{v} .)\end{array}$ & $\begin{array}{l}I \frac{1}{2}-I \frac{1}{2} \\
3 \frac{1}{2}-2 \frac{1}{2} \\
2 \frac{1}{2}-I \frac{1}{2}\end{array}$ & $\begin{array}{c}\lambda \\
3403.35 \\
3408.78 \\
3422.76\end{array}$ & 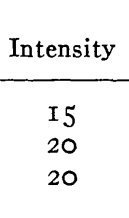 & \\
\hline $\begin{array}{l}\mathrm{a}^{4} \mathrm{D}-\mathrm{y}^{4} \mathrm{P}^{0} \\
(2.4 \mathrm{v} .)(6 . \mathrm{I} \mathrm{v} .)\end{array}$ & $3 \frac{1}{2}-2 \frac{1}{2}$ & 3368.06 & 20 & $0-I$ \\
\hline $\begin{array}{l}\mathrm{a}^{4} \mathrm{D}-\mathrm{z}^{4} \mathrm{~F}^{0} \\
(2.4 \mathrm{v} .)(6.4 \mathrm{v} .)\end{array}$ & $\begin{array}{l}I \frac{1}{2}-2 \frac{1}{2} \\
2 \frac{1}{2}-3 \frac{1}{2} \\
3 \frac{1}{2}-4 \frac{1}{2}\end{array}$ & $\begin{array}{l}3 \text { I } 20.37 \\
3 \text { I } 25.00 \\
3 I 32.06\end{array}$ & $\begin{array}{l}\text { I5 } \\
20 \\
20\end{array}$ & $\begin{array}{l}\text { O-In } \\
\text { O-I } \\
\text { I }\end{array}$ \\
\hline
\end{tabular}


The simultaneous presence of $[F e \mathrm{II}]$ and of transauroral $[S \mathrm{II}]$ in the emitting atmospheres of B I985 and WY Gem is very interesting. They also appear simultaneously in several other stars: $\eta$ Carinae, $\mathrm{HD}$ 45677, VV Cephei, MWC I 7 , + $\mathrm{II}^{\circ} 4673$ at certain stages. This should be related to the fact that in certain objects (e.g., MWC I 7 and $\left.+\mathrm{II}^{\circ}{ }_{4673}\right)[\mathrm{Fe} \mathrm{II}]$ and $[N \mathrm{II}]$ appear together. It also happens that $[\mathrm{Fe} \mathrm{II}]$ and $[\mathrm{O} \mathrm{I}]$ are observed in the same bright-line star (e.g., MWC I7, $\mathrm{HD}_{45677}$, and certain stages of novae).

\section{REMARKS ON THE TRANSITION PROBABILITIES OF THE [ $F e$ II] LINES}

The simultaneous appearance of the forbidden lines of $[F e$ II] and of other elements throws some light upon the problem of the transition probabilities of the $[F e \mathrm{II}]$ lines. We consider here the probabilities of transitions between various terms of the $3 \mathrm{~d}^{6} 4 \mathrm{~s}$ and $3 \mathrm{~d}^{7}$ configurations; no computed probabilities are as yet available for such a complex case.

The intensity $I$ of a forbidden line of frequency $\nu$ is given by

$$
I=\frac{N A_{\mathrm{I}} h \nu}{B+C+A_{\mathrm{I}}+A_{2}+\ldots}
$$

where $N$ is the number of atoms arriving per second in the upper state; $A_{1}, A_{2}, \ldots$ are the probabilities of line emissions; $B$ is the probability of removal from the upper level by a collision either of the first kind (gain of energy) or of the second kind (loss of energy); and $C$ is the probability of removal by absorption. If $A$ is much greater than $B$ and $C$ (the normal case in nebulae), we have

$$
I=\frac{N h \nu}{\mathrm{I}+\frac{A_{2}}{A_{\mathrm{I}}}+\ldots}
$$

In the extreme case where $B+C$ is much greater than $A_{\mathrm{I}}+A_{2}+\ldots$, we have

$$
I=\frac{N A_{\mathrm{t}} h \nu}{B+C}
$$

In the intermediate cases of shells all factors should be considered.

We know that $[\mathrm{Fe}$ II] has never been observed in any planetary nebula, even if the excitation is low enough. For example, in $\mathrm{BD}+30^{\circ} 3639,[\mathrm{Fe} \mathrm{II}]$ is absent, whereas $[O \mathrm{II}]$ and $[N \mathrm{II}]$ are strong; in IC $4 \mathrm{I} 8,[O \mathrm{II}]$ is also very strong and [O III] is weaker; in neither case does $[F e \mathrm{II}]$ appear. This is true for all planetaries even when $[O \mathrm{I}]$ is present. This absence may be attributed to one of two causes: the relatively low abundance of iron compared to the lighter elements or the distribution of electronic excitation among many levels. From the observation in nebulae of $[\mathrm{Fe}$ vII] and $[\mathrm{Fe}$ vI], which have only a small number of metastable levels and for which the transition probabilities are known, 5 it appears that iron must be less abundant than sulphur (by a factor of the order of Io), nitrogen, and oxygen (by a factor of 100). ${ }^{6}$ Within the range of electron kinetic energy between 1.6 and 4.8 volts, $F e$ II possesses 50 sublevels, from a ${ }^{4} \mathrm{P}_{23 / 6}\left(\mathrm{I} .66 \mathrm{v}\right.$.) to $\mathrm{c}^{2} \mathrm{D}_{\mathrm{I} / / 2}(4.72 \mathrm{v}$.), into which the $\mathrm{Fe}^{+}$atoms may be brought by collisions; the average distance between two sublevels is only about 0.06 volt. But, on the other hand, the collisional cross-section for a collision of the first kind between an electron and an atom is large when the kinetic energy of the elec-

${ }^{5}$ S. Pasternack, $A p$. J., 92, I29, I940.

${ }^{6}$ Bowen and Wyse, Lick Obs. Bull., r9, No. 495, I939. 
tron is only slightly above that necessary to bring the atoms to a higher level; for electrons of higher velocity the collisional cross-section falls off rapidly. The presence of a large number of sublevels will thus increase the exciting efficiency of the collisions with electrons, and it is by no means certain that the populations of the $F e$ II levels will be much reduced, in comparison with atoms with few low levels, such as $S$ II, $N$ II, or others. A more definite statement is at present impossible because the collisional cross-section is very sensitive to the structures of the colliding particles and to the relative velocities. Under nebular conditions the effects of de-excitation by collisions of the first or the second kind and by absorptions are unimportant. The only major factor is the number of atoms arriving per second in the excited states.

Thus, the absence of $[\mathrm{Fe} \mathrm{II}]$ in nebulae suggests that under nebular conditions the combined effect of lower abundance and of the larger number of metastable states reduces considerably the intensity of the $[F e$ II] lines as compared to $[O \mathrm{I}],[N \mathrm{II}]$, and $[S \mathrm{II}]$.

The observations show that the situation is quite different in the emitting layers of stars, such as B I985, WY Gem, $\eta$ Carinae, and others. In these shells the electron pressure is much higher than in most nebulae, as is shown by the predominance of the transitions of auroral type. The de-excitation of certain excited states by collisions or absorptions is no longer negligible.

The proximity of the metastable and ordinary excited levels of $\mathrm{Fe}$ II would tend to increase their de-excitation by collisions or absorptions, compared to $[O \mathrm{I}],[N \mathrm{II}]$, or $[S \mathrm{II}]$, in which the ordinary levels lie rather high above the metastable states. Hence, unless we assume very peculiar abundances, we are tempted to seek the explanation for the strength of the $[F e$ II] lines in relatively high probabilities of these forbidden transitions.

In a nebula of low excitation, the lines of $[\mathrm{Fe}$ II] are much weaker than the lines of $[N$ II] and $[S \mathrm{II}]$ by a factor of the order of Ioo. On the contrary, in certain stellar shells, despite the unfavorable conditions of de-excitation by collisions or absorptions, the $[F e \mathrm{II}]$ lines are stronger than $[N \mathrm{II}]$ or $[S \mathrm{II}]$. The transition probabilities for the auroral or transauroral lines are $2.2 \mathrm{sec}^{-1}$ for $[O \mathrm{I}] ; 2.2 \mathrm{sec}^{-\mathrm{I}}$ for $[N \mathrm{II}]$; and 0.32 and $0 . \mathrm{I} 3 \mathrm{sec}^{-1}$ for $[S \mathrm{II}]$. The excitation potentials of $[S \mathrm{II}]$ and $[\mathrm{Fe}$ III] are practically the same. It is difficult to estimate how much of this phenomenon is due to ionization effects and how much to the transition probabilities. But it appears safe to assume that the strongest lines of $[F e \mathrm{II}]$ have a transition probability appreciably higher than the forbidden lines of $[O \mathrm{I}]$, $[N$ II] , and $[S$ II], the ratio being of the order of Io0. A similar result would be obtained for configuration $3 \mathrm{~d}^{5}$ of $[\mathrm{Cr} \mathrm{II}]$.

MCDONALd ObSERVATORY January I $94 \mathrm{I}$ 